\title{
Contrast Agent Administered Identifier
}

National Cancer Institute

\section{Source}

National Cancer Institute. Contrast Agent Administered Identifier. NCI Thesaurus. Code C69278.

An identifier for a contrast agent that was administered. 